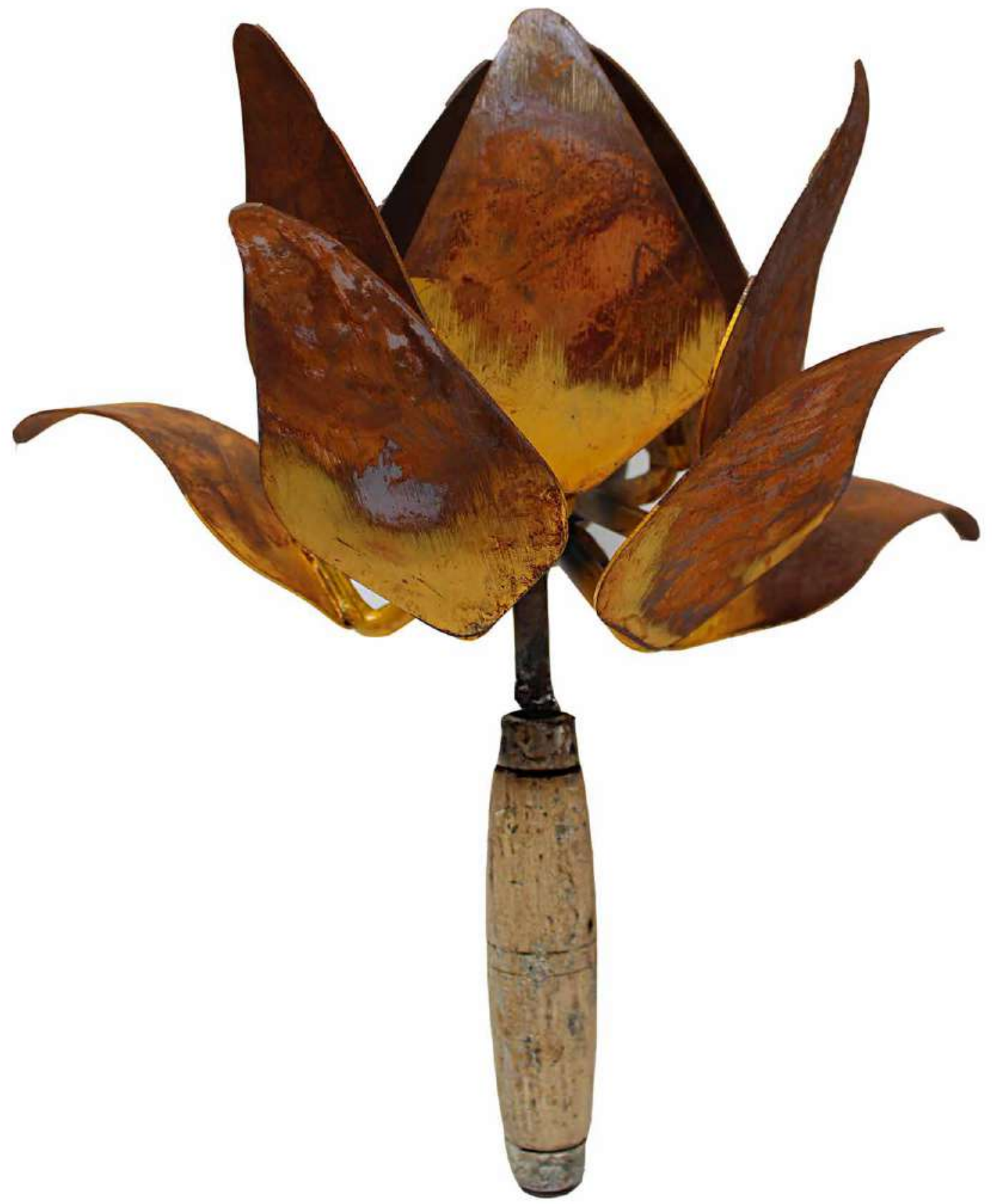

Yamith Quiroz David

Nuevas vegetaciones IV

De la serie El mito de flora

Escultura, palustres de hierro,

cabo de madera

$38 \times 23 \times 15 \mathrm{~cm}$

2020

Medellín 


\title{
Restitución de tierras en Antioquia, Colombia. Base para la consolidación del sujeto de derecho mujer y sus repercusiones en el posacuerdo*
}

\author{
Natalia María Posada Pérez (Colombia)**
}

\section{Resumen}

En la tradición jurídica colombiana las mujeres han sido desconocidas e invisibilizadas como dueñas de la tierra, con capacidad de decisión y de administración. El propósito de este artículo es analizar la construcción del sujeto de derecho mujer en torno a la tierra, a partir del seguimiento a la posición de las mujeres en la normatividad rural colombiana. Para ello se retoma el testimonio de campesinas antioqueñas reclamantes de tierras, con la hipótesis de que la reparación bajo la Ley 1448 de 2011 es una pieza clave para el reconocimiento de las mujeres en tanto sujetos de derecho. Con el auxilio de teorías feministas y la perspectiva de género, se presenta la trayectoria de campesinas en torno a la tierra desde el anonimato jurídico, la pérdida del terreno en el marco del conflicto armado y la reclamación del predio bajo la citada Ley, cerrando con el reconocimiento de la titularidad de derechos a través de la figura de la reclamación y lo que esto significa en un contexto de posacuerdo mediante la resignificación de la victimización.

\section{Palabras clave}

Conflicto Armado; Posconflicto; Sujeto de Derecho Mujer; Perspectiva de Género; Acceso a la Tierra; Colombia.

Fecha de recepción: febrero de 2020 - Fecha de aprobación: julio de 2020

\footnotetext{
* Este artículo es producto de dos proyectos de investigación articulados: Sistema de Información y Comunicación para la Restitución de Tierras en Antioquia: Estudio de Caso con Enfoque de Género, 2014-2016 (CODI Acta 670 de 2013); y Transición y construcción de paz en Antioquia, 2019 (CODI 774). Ambos avalados por el Comité para el Desarrollo de la Investigación, Universidad de Antioquia, Colombia.

** Politóloga. Magíster en Estudios Socioespaciales. Grupo Medio Ambiente y Sociedad, y Grupo Cultura, Violencia y Territorio, Facultad de Ciencias Sociales y Humanas. Docente de la Facultad de Derecho y Ciencias Políticas, Universidad de Antioquia UdeA. Calle 67 N. ${ }^{\circ}$ 53-108, Medellín, Colombia. Correo electrónico: natalia.posada@udea.edu.co - Orcid: 0000-0002-1853-2377 - Google Scholar: https://scholar.google.com/citations?hl=es\&authuser=2\&user=G68LMAkAAAAJ
} 


\title{
Cómo citar este artículo
}

Posada Pérez, Natalia María. (2020). Restitución de tierras en Antioquia, Colombia. Base para la consolidación del sujeto de derecho mujer y sus repercusiones en el posacuerdo. Estudios Políticos (Universidad de Antioquia), 59, pp. 150-175. DOI: 10.17533/udea.espo.n59a07

\section{Land Restitution in Antioquia, Colombia. Basis for the Consolidation of Women as Subjects of Law and its Repercussions on the Post-Agreement}

\begin{abstract}
In the Colombian legal tradition, women have not been recognized and acknowledged as proper land owners, they have been regarded as beings without decision-making or administration abilities The objective of this article is to analyze the construction of Women's land and property rights, based on the monitoring of the position of women in Colombian rural regulations. For this purpose, the study analyzes the testimony of Antioquia women peasants land claimants, guided by the hypothesis that reparation under Law 1448 of 2011 is a key piece for the recognition of women as subjects of law. Based on feminist theories and the gender perspective, the article presents the history of women peasants around the land. A history marked by legal anonymity, the loss of land in the framework of the armed conflict, the claim of the property under the mentioned Law, and which closes with the recognition of the ownership of rights through the figure of the claim and what this means in a post-agreement context, and promoting the resignification of victimization.
\end{abstract}

\section{Keywords}

Armed Conflict; Post-Conflict; Woman Subject of Law; Gender Perspective; Access to Land; Colombia. 


\section{Introducción}

Las disputas relacionadas con la concentración de la tierra en Colombia abrieron paso al conflicto armado interno. Sobresale el departamento de Antioquia, uno de los más afectados por la guerra, en regiones como el Urabá, en virtud de su valor geoestratégico, y el Oriente, con municipios asolados por el abandono forzado (Coll, 2015).

Mapa 1. Municipios de San Carlos (1), Granada (2)

y Urabá (3), departamento de Antioquia.

\section{SUBREGIONES Y MUNICIPIOS}

[152]

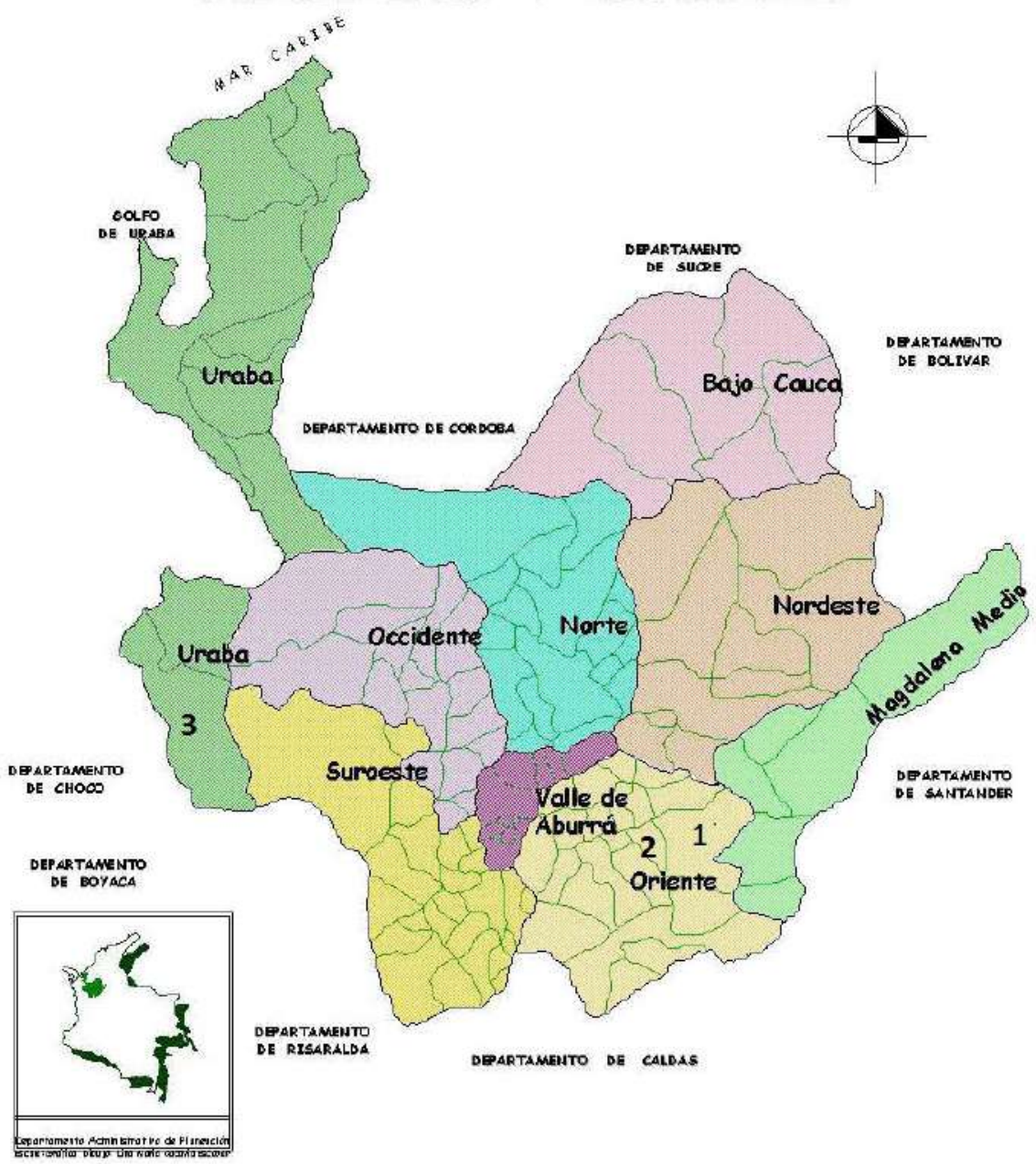

Fuente: tomado de Alcaldía El Peñol (s. f.). 
A la luz de la justicia transicional, en Colombia se han prescrito dispositivos como la restitución de tierras para reparar a las víctimas de violaciones de derechos humanos y del derecho internacional humanitario (ONU, Resolución 60/147 del 16 de diciembre de 2005). En este contexto, las mujeres han tenido una presencia constante, pero soslayada, que se suma a las limitaciones que enfrentan para acceder a la tierra, empeoradas con ocasión del conflicto armado. Justamente, el objetivo del artículo es analizar los procesos de restitución de tierras para mujeres en la subregión del Urabá, y en los municipios de San Carlos y Granada del Oriente antioqueño, al amparo de la Ley 1448 de 2011. En este caso, la restitución es la base para entender la configuración de las mujeres como sujetos de derecho en torno a la tierra, en tanto es uno de los mecanismos de reparación a las víctimas del conflicto armado incorporados en la citada ley y que además tiene repercusiones en el posacuerdo mediante la resignificación de la victimización.

La configuración de la subjetividad jurídica se basa en la interpretación de trayectorias de mujeres campesinas respecto a la tenencia, uso y gozo de la tierra, en un proceso que comprende el anonimato jurídico, la victimización con la pérdida del terreno en el marco del conflicto armado, la reclamación del predio bajo la Ley 1448 de 2011, hasta el reconocimiento de la titularidad de derechos vía restitución y lo que esto representa tras la firma del Acuerdo de Paz en 2016 entre las Fuerzas Armadas Revolucionarias de ColombiaEjército del Pueblo (FARC-EP) y el Estado colombiano.

Para ello, se establecen tres perfiles de campesinas: i) mujeres despojadas sin proceso de restitución; ii) mujeres reclamantes bajo la Ley 1448 de 2011; y iii) mujeres ya restituidas, de cara a los procesos de reparación, en medio de los cuales no es extraño la invisibilidad de las campesinas a través del enfoque familista que impide conocer a fondo la situación de estas mujeres víctimas de despojo o abandono forzado (Coll, 2015), ya que el enfoque prioriza los intereses de la familia por encima de los de sus miembros, dando por sentado que de esta manera se garantizan los derechos de los integrantes del núcleo familiar (Guzmán y Chaparro, 2013). Al quebrar esta perspectiva, se detalla la antiquísima relación de las mujeres con la tierra, lo que sin duda abre una posibilidad para las campesinas comprometidas con la defensa del Acuerdo de Paz, para quienes la filiación con sus tierras las impulsa a no declinar a este llamado, pese a los riesgos para ejercer liderazgos sociales en el país (El Espectador, 2019, marzo 6).

En cualquier caso, el acceso a la tierra por parte de las mujeres se relaciona con las dinámicas del conflicto armado y su afectación sobre las 
campesinas en Antioquia, aunque al mismo tiempo las precede y las trasciende en la medida en que el asunto atañe a cuestiones como la propiedad y los regímenes patrimoniales, si bien no se agota en el ámbito del derecho privado. En este sentido, la puesta en marcha de la Ley 1448 de 2011 deja claro que un título de propiedad no basta y, por lo mismo, el acceso de las mujeres a la tierra tiene que ver con cuestiones como el empoderamiento y la autonomía, pero además con la seguridad personal, familiar y comunitaria, sumado a las posibilidades efectivas de autorrealización.

\section{Sujeto de derecho en torno a la tierra: luchas por la definición y el reconocimiento}

Hablar de «sujeto de derecho» implica un proceso de reconocimiento y legitimación social que se condensa en la legalidad. Así, el sujeto de derecho es un título clave para materializar las promesas de la modernidad, rastreables desde las teorías iusnaturalistas. Este apelativo, ubica al hombre —varón-en tanto ser de derecho, en virtud de su naturaleza. La conceptualización pasa de la dignidad del hombre renacentista al hombre como portador de derechos a partir del siglo XVII. Del renacimiento se conserva la especificidad del hombre para distinguirlo de los demás seres naturales, pero ahora su dignidad remite a la libertad para hacerse a sí mismo y a la responsabilidad de llegar a ser, sobre la base del carácter moral del sujeto de derecho y la necesidad recíproca que cada sujeto tiene de los demás (Zarka, 1999).

En este contexto, en Noveaux essais sur l'entendement humain Leibniz instituye el concepto «sujeto de derecho», para lo cual reformula el derecho en torno a la noción de cualidad moral, propia de la persona. El autor sostiene que el prójimo es crucial en lo que se refiere a la identidad personal, en tanto constata la emergencia de la alteridad a través de la propia conciencia, la ipseidad. Por consiguiente, la identidad personal y moral transita y se conserva a través de las relaciones con los otros, la intersubjetividad (Leibniz citado en Zarka, 1999).

Lo anterior permite dilucidar el rol de las campesinas reclamantes de tierras en tanto sujetos de derecho de la Ley 1448 de 2011, considerando los procesos subyacentes que para las mujeres comienzan por la exclusión de una condición ideada por y para varones, abriendo camino a la unanimidad en los discursos misóginos de todos los tiempos (Kelly citado en Amorós, 2000).

En Latinoamérica, las prácticas colonizadoras insuflan el concepto «sujeto de derecho» frente a las luchas por el pleno ejercicio de la ciudadanía, 
abanderadas por los movimientos de mujeres y los feminismos. Retomando a Leibniz (citado en Zarka, 1999), la dimensión intersubjetiva es la base para el reconocimiento y la titularidad de derechos, que en este caso involucra la propiedad de la tierra y las luchas fraguadas por las mujeres.

Entre las líneas de debate jurídico acerca de la propiedad, trazadas por la teoría feminista latinoamericana, sobresale el análisis de los diferentes impedimentos que tienen las mujeres para acceder a ella en contextos de conflicto armado y desplazamiento forzado. Estos estudios gozan de especial importancia para entender la brecha entre la consagración legal de los derechos de las mujeres y las dificultades cotidianas que enfrentan para titular bienes (Alviar, 2008). El derecho de propiedad alude a la capacidad de gozar, usar y disponer de un bien de acuerdo a sus limitaciones legales y en consideración a su función social. Incluye la posibilidad de contar con recursos de una sociedad sin impedimentos legales para su libre acceso, además de contemplar la producción de riqueza a través del trabajo (Alviar, 2008).

En la legislación latinoamericana que promueve el acceso de las mujeres a la propiedad de la tierra y se reconocen tres líneas que atienden respectivamente a: i) la vinculación de la identidad femenina con la maternidad y el acceso a la propiedad; ii) la consagración del acceso privilegiado a la propiedad; y iii) las tensiones que origina este derecho entre los grupos marginados.

En la primera línea, el liberalismo conoce de las restricciones para el acceso a la propiedad en función de la raza, clase o género, por lo que prevé la intervención a favor de la familia y la madre en lo que respecta a la distribución de los bienes en la sociedad conyugal. En consecuencia, de alguna forma se reconoce el trabajo reproductivo endilgado a las mujeres, fundamental para justificar el establecimiento y la separación radical entre las esferas pública y privada (Alviar, 2008). En las sociedades contemporáneas, la identidad femenina, el trabajo reproductivo y el acceso a la propiedad se afianzan en una amalgama entre discursos sociales y normas jurídicas denominadas «configuración social» (Alviar, 2008), que abarcan las representaciones de «lo femenino» dentro de un sistema jurídico, ligadas a las relaciones sociales reguladas que devienen en la producción del sujeto político mujer.

La segunda vertiente consagra el acceso privilegiado a la propiedad, en la que el Estado liberal interviene en pro de las mujeres víctimas de 
desplazamiento forzado bajo el enfoque de género, mientras que la teoría feminista se debate entre la histórica vulneración de las mujeres para justificar la asistencia estatal, mal visto por los feminismos posmodernos que lo entienden como un pretexto para extender el sometimiento de las mujeres (Alviar, 2008).

Por su parte, el tercer eje analítico evalúa las tensiones que surgen entre los grupos marginados por el reconocimiento de los derechos a la propiedad. Aquí se confronta el privilegio del derecho de posesión como requisito para la propiedad con el principio de igualdad de género, en cuyo caso la tierra es disputada entre mujeres que son madres y campesinos que laboran la tierra.

En Colombia, lo anterior redunda en el debate sobre la redistribución material y el reconocimiento de la identidad (Fraser, 1997), observable en la ruralidad mediante dinámicas que evidencian la brecha de género en la propiedad de la tierra latinoamericana (Deere y León, 2000). Esto, porque en muchos casos se desconoce a las mujeres como agricultoras por ser una labor tradicionalmente asociada a los hombres, de lo que resulta el privilegio masculino para la adjudicación de tierras cuando se disputa entre campesinos desposeídos y mujeres cabeza de hogar que también se han dedicado al campo, pero se les desconoce la misma intensidad que a los varones porque, obviamente, el trabajo doméstico las obliga a dividir el tiempo entre otras funciones.

Con la restitución de tierras bajo la Ley 1448 de 2011 se añaden nuevas dificultades para las campesinas, pero también germinan posibilidades de transformación que, en principio, exigen del reconocimiento de las mujeres como sujetos de derecho en contextos de antiguas disputas por la tierra.

Acerca de la restitución, la producción académica en Colombia gira en torno a ejes más amplios, como son la estructura agraria del país (Albán, 2011; CNMH, 2013), las problemáticas del sector rural (Machado, 2011) y el desplazamiento forzado (Ibáñez y Querubín, 2004). De estos nodos se desprenden estudios sobre la justicia transicional y los derechos humanos (Valdivieso, 2012), las medidas de reparación a las víctimas (Estrada y Rodríguez, 2014) y la restitución de tierras como uno de los mecanismos reparadores que deriva de la Ley 1448 de 2011 (Uprimny y Sánchez, 2010; Vélez, 2013). 
En esta escala, hay pocos estudios con perspectiva de género, salvo publicaciones sobre el desplazamiento forzado (Meertens, 2011), la propiedad para las mujeres en clave de justicia de género (León, 2008), las dificultades específicas que atraviesan para acceder a la tierra (PNUD, 2011) y la implementación de la Ley de Víctimas y Restitución de Tierras desde un enfoque diferencial (Rodríguez, 2014).

Lo anterior es la oportunidad para desarrollar investigaciones del tipo que interesan en este artículo, centradas en la pregunta por la tierra y la restitución para las mujeres. Los estudios rastreados aportan a la comprensión de los regímenes de propiedad, en sintonía con el papel del Estado y los modelos de desarrollo imperantes en el campo colombiano. También se discute el conflicto armado interno, el cual, en este caso, articula la transición de las campesinas como víctimas hacia la titularidad de derechos sobre la tierra por vía de la reparación legal.

\section{Metodología}

El estudio incorporó los resultados de dos investigaciones cualitativas sobre restitución de tierras para campesinas en Antioquia y estrategias de construcción de paz territorial, respectivamente. Mediante el estudio de caso múltiple se contrastó la experiencia de mujeres reclamantes en los municipios de San Carlos y Granada, y en el Urabá antioqueño en diferentes etapas del proceso de reparación; igualmente, se aplicó un muestreo no probabilístico con apoyo de organizaciones campesinas y feministas comprometidas con el tema.

Durante el proceso de recolección de información se aplicaron entrevistas semiestructuradas y a profundidad, acompañadas por la firma del consentimiento informado para divulgar los testimonios; también se consultaron perfiles académicos, de funcionarias públicas y de activistas con trayectoria en la cuestión; igualmente, se revisaron fuentes secundarias para auxiliar la discusión de resultados, en la que se tuvieron en cuenta los testimonios de campesinas recolectados en 2015, con las que nuevamente se conversó en 2019 gracias al segundo proyecto de investigación, de cara al seguimiento al proceso de restitución y sus alcances en el posacuerdo. Por último, la normatividad nacional e internacional sobre la cuestión muestra los tejemanejes jurídicos del problema, sintetizados en las principales normas entre 1961 y 2011 (véase cuadro 1). 
Cuadro 1. Normatividad nacional e internacional sobre mujeres, ruralidad y tierras.

\begin{tabular}{|c|c|c|c|}
\hline 1961 & 1979 & \multicolumn{2}{|c|}{1991} \\
\hline $\begin{array}{l}\text { Ley } 135 \text { de 1961: } \\
\text { Reforma Social } \\
\text { Agraria. } \\
\text { Creación del Incora } \\
\text { y de la Unidad } \\
\text { Agrícola Familiar. No } \\
\text { declara igualdad entre } \\
\text { hombres y mujeres. }\end{array}$ & $\begin{array}{l}\text { Convención para } \\
\text { la Eliminación de } \\
\text { Todas las Formas } \\
\text { de Discriminación } \\
\text { contra la Mujer } \\
\text { (CEDAW). Aprobada } \\
\text { en Colombia con Ley } \\
51 \text { de } 1981 . \\
\text { Obligatoriedad: } \\
\text { Sentencia C 507 } \\
\text { de 2004, Corte } \\
\text { Constitucional. } \\
\text { Art. 14: Estados } \\
\text { tendrán en cuenta } \\
\text { problemática de la } \\
\text { mujer rural. } \\
\text { Art. 16: Eliminación } \\
\text { de desigualdad } \\
\text { en el matrimonio: } \\
\text { Cuando la sociedad } \\
\text { se disuelva en } \\
\text { desplazamiento } \\
\text { forzado }\end{array}$ & $\begin{array}{l}\text { Declaración de } \\
\text { Ginebra para la } \\
\text { Mujer Rural. } \\
\text { Contribución de } \\
\text { las mujeres rurales } \\
\text { al desarrollo } \\
\text { socioeconómico y a } \\
\text { la democracia. }\end{array}$ & $\begin{array}{l}\text { Constitución } \\
\text { Política de } \\
\text { Colombia. } \\
\text { Reconocimiento } \\
\text { del derecho a la } \\
\text { tierra. } \\
\text { Art. 65: Protección } \\
\text { estatal a la } \\
\text { producción de } \\
\text { alimentos. } \\
\text { Art. 43: Especial } \\
\text { protección del } \\
\text { Estado a mujeres } \\
\text { cabeza de hogar. }\end{array}$ \\
\hline 1994 & \multicolumn{2}{|c|}{1995} & 1996 \\
\hline $\begin{array}{l}\text { Ley } 160 \text { de 1994: } \\
\text { Reforma Agraria y } \\
\text { Desarrollo Rural. } \\
\text { Atención preferencial } \\
\text { a campesinas jefas de } \\
\text { hogar, desprotegidas } \\
\text { y carentes de tierra o } \\
\text { por insuficiencia. }\end{array}$ & $\begin{array}{l}\text { Reglamentación del } \\
\text { Incora a Ley } 160 \text { de } \\
1994 . \\
\text { Acuerdo } 018 \text { de } \\
\text { 1995: Acceso } \\
\text { a la tierra para } \\
\text { población campesina } \\
\text { desplazada por la } \\
\text { violencia. }\end{array}$ & $\begin{array}{l}\text { Conferencia Mundial } \\
\text { sobre la Mujer } \\
\text { (Beijing). } \\
\text { Reconocimiento } \\
\text { de incremento } \\
\text { de la pobreza, } \\
\text { especialmente entre } \\
\text { mujeres rurales. }\end{array}$ & $\begin{array}{l}\text { Declaración } \\
\text { de Roma sobre } \\
\text { seguridad } \\
\text { alimentaria. } \\
\text { Aporte fundamental } \\
\text { de mujeres rurales } \\
\text { de países en } \\
\text { desarrollo, para } \\
\text { detener migración } \\
\text { campo-ciudad. }\end{array}$ \\
\hline
\end{tabular}


Restitución de tierras en Antioquia, Colombia. Base para la consolidación del sujeto...

Cuadro 1. (Continuación)

\begin{tabular}{|c|c|c|c|}
\hline 1997 & 2002 & 2003 & 2008 \\
\hline $\begin{array}{l}\text { Ley } 387 \text { de } 1997 . \\
\text { Incorporación de la } \\
\text { población desplazada } \\
\text { a los programas } \\
\text { de subsidios de } \\
\text { tierras; diseño e } \\
\text { implementación } \\
\text { del programa de } \\
\text { Protección de Tierras }\end{array}$ & $\begin{array}{l}\text { Lay } 731 \text { de 2002: } \\
\text { Mujer Rural. } \\
\text { Mejoramiento de } \\
\text { calidad de vida } \\
\text { priorizando las de } \\
\text { más bajos recursos; } \\
\text { medidas específicas } \\
\text { en favor de equidad } \\
\text { entre hombres y } \\
\text { mujeres rurales. } \\
\text { Reglamentación a } \\
\text { cargo del Ministerio } \\
\text { de Agricultura. }\end{array}$ & \begin{tabular}{|l|} 
Ley 812 de $2003:$ \\
PND $2002-2006$. \\
Reforma a Ley 160 \\
de 1994 . Supresión \\
de adjudicación \\
de tierras a cambio \\
de subsidios \\
por fuera de la \\
economía tradicional \\
campesina; contrato \\
de asignación o \\
tenencia provisional; \\
impulso de la \\
agroindustria.
\end{tabular} & $\begin{array}{l}\text { Ley } 1257 \text { de } 2008 . \\
\text { Consideración del } \\
\text { daño patrimonial } \\
\text { a campesinas; } \\
\text { responsabilidad } \\
\text { estatal en políticas } \\
\text { públicas para } \\
\text { el acceso de las } \\
\text { mujeres a servicios } \\
\text { y cumplimiento de } \\
\text { derechos; atención } \\
\text { diferenciada. }\end{array}$ \\
\hline \multicolumn{2}{|c|}{2010} & \multicolumn{2}{|c|}{2011} \\
\hline $\begin{array}{l}\text { Decreto } 2969 \text { de } 2010 \\
\text { de Ley } 1257 \text { de } 2008 . \\
\text { Comisión Nacional } \\
\text { Intersectorial para } \\
\text { Promoción y Garantía } \\
\text { de Derechos Sexuales } \\
\text { y Reproductivos. }\end{array}$ & $\begin{array}{l}\text { Ley } 1377 \text { de } 2010 . \\
\text { Reforestación } \\
\text { comercial, } \\
\text { explotación intensiva } \\
\text { de recursos forestales. }\end{array}$ & $\begin{array}{l}\text { Ley } 1450 \text { de } 2011: \\
\text { PND } 2010-2014 . \\
\text { Anuncio de política } \\
\text { pública nacional de } \\
\text { equidad de género } \\
\text { con planes a favor de } \\
\text { mujeres desplazadas } \\
\text { (Auto } 092 \text { de 2008). } \\
\text { Enunciativo, sin } \\
\text { medidas concretas } \\
\text { para desplazamiento } \\
\text { forzado, violencia } \\
\text { de género, derechos } \\
\text { humanos de las } \\
\text { mujeres. }\end{array}$ & $\begin{array}{l}\text { Ley } 1448 \text { de } 2011 . \\
\text { Enfoque } \\
\text { diferencial; } \\
\text { eliminación de } \\
\text { esquemas de } \\
\text { discriminación; } \\
\text { limitación de } \\
\text { restitución de } \\
\text { tierras dejando por } \\
\text { fuera otro tipo de } \\
\text { bienes; atención } \\
\text { preferencial a } \\
\text { mujeres cabeza de } \\
\text { hogar en trámites } \\
\text { administrativos } \\
\text { y judiciales; } \\
\text { favorecimiento de } \\
\text { organizaciones de } \\
\text { mujeres en proceso } \\
\text { de reparación; } \\
\text { restitución a favor } \\
\text { de los cónyuges. }\end{array}$ \\
\hline
\end{tabular}

Fuente: elaboración propia. 
En los resultados estos elementos se leen en el contexto del conflicto armado colombiano y sus consecuencias devastadoras para las mujeres campesinas, algunas de las cuales han visto en la Ley 1448 de 2011 una oportunidad de recomponer sus proyectos de vida, a propósito de la justicia transicional que inició en el país con la Ley de Justicia y Paz en 2005.

\section{Resultados}

La persistencia de la brecha agraria en Colombia se alimenta del despojo de tierras y de los territorios colectivos en manos de grupos armados ilegales, de los macroproyectos de inversión empresarial y de las políticas agrarias emprendidas en la última década (Comisión Colombiana de Juristas, 2011). En el caso del desplazamiento forzado, las personas migran con frecuencia hacia las periferias urbanas, obligadas a subsistir en condiciones precarias. Esto se refuerza con la discriminación que suelen afrontar en los nuevos entornos, los hombres en el plano laboral y las mujeres en el ámbito comunitario (Meertens, 2011).

Otro tanto viene por cuenta de las arremetidas violentas perpetradas por los actores en conflicto, las cuales también difieren debido al género. A [160 ] menudo los hombres son reclutados a la fuerza para el fortalecimiento de las tropas, son asesinados o desaparecidos, mientras que las mujeres son objeto de violencias de género — abuso sexual, prostitución forzada-, violencia basada en género —-servicios domésticos forzosos- (Meertens, 2011) y de manera intempestiva deben asumir la jefatura del hogar y el aprovisionamiento material de este ante la muerte o desaparición del cónyuge.

Ni qué decir acerca de los impactos de la informalidad en la tenencia de la tierra. En Antioquia, un alto porcentaje de mujeres no son propietarias, en general, acceden a este recurso por medio de sus parejas, padres u otros familiares varones, quienes tampoco han forjado una tradición de formalización de los predios, quedando igualmente a la deriva frente a potenciales actos de despojo (Zuluaga, 2011).

Entre las formas de perder la tierra, una de las regiones más afectadas por el abandono forzado es el Oriente antioqueño. En los municipios de San Carlos y Granada se imposibilitó el acceso y disfrute de los predios campesinos debido a la violencia generalizada que obligó a la población a emigrar. Por el contrario, en el Urabá antioqueño ha proliferado el despojo a través de la 
violencia ejercida por actores armados mediante estrategias legales e ilegales, dando como resultado la apropiación total o parcial de las tierras en cabeza de los perpetradores o a favor de terceros.

Los resultados que se presentan conjugan los testimonios de campesinas sancarlitanas, granadinas y urabaenses que perdieron sus tierras a causa del conflicto armado, algunas tuvieron que abandonarlas, mientras que otras fueron víctimas del despojo. La síntesis se clasifica en tres bloques: mujeres que fueron despojadas y no accedieron a la restitución de tierras; mujeres que también sufrieron el despojo y a la fecha tienen un proceso activo de reparación bajo la Ley 1448 de 2011; y campesinas ya restituidas en el marco de la citada ley.

\subsection{Mujeres despojadas sin proceso de restitución de tierras}

Sancarlitanas de toda la vida, madre e hija a quienes despojaron de sus predios en la década de 1980 junto con el resto de la familia, migraron hacia Cali con el escaso dinero que recibieron a cambio del fundo, otra de las modalidades para despojar a la gente, sin embargo, hasta el momento ni ellas mismas lo sabían.

Con la migración forzada vino la inestabilidad material que signó los proyectos de vida personales y familiares. Igualmente, tras el retorno se prolongó la inestabilidad, al menos durante los primeros años de la década del 2000, cuando decidieron regresar al municipio, a sabiendas de que persistía el conflicto armado en la zona. En todo caso, «sintieron el llamado de la tierra», cualquier cosa en lugar de permanecer en aquella ciudad receptora, tan violenta para criar a las nuevas generaciones de la familia (campesina de San Carlos, comunicación personal, 3 de marzo, 2015).

En la actualidad, desconocen el estado del predio malvendido. Lo importante es afianzarse en la nueva vivienda que lograron construir con el esfuerzo familiar, la cual, a su juicio, deberá titular el padre cabeza de hogar. Paralelamente, las dos campesinas tratan de obtener un crédito de vivienda que más tarde puedan legar a los niños. No hizo falta la restitución, pues la ven como un proceso engorroso que además no podrían asumir porque, en su entendido, no fueron víctimas de despojo, ya que recibieron dinero a cambio del terruño (campesina de San Carlos, comunicación personal, 12 de junio, 2019). 


\subsection{Mujeres reclamantes con proceso activo bajo la Ley 1448 de 2011}

Cuatro víctimas de despojo en el Urabá antioqueño se animaron a reclamar las tierras, algunas no tan convencidas, sin embargo, en medio del temor y la incredulidad, hoy tienen demanda en curso ante el Estado. Antes de ser desplazadas, estas mujeres habitaban las fincas con sus familias, pese a que ninguna era la propietaria. Tras años de dedicación a las labores domésticas y agrícolas, hoy reclaman en nombre de sus padres, hermanos o esposos, a quienes reconocen como los titulares de la tierra por derecho propio. También está la figura de la madre cabeza de familia que aspira a que le devuelvan la tierra en función de la maternidad (campesina de Urabá, comunicación personal, 2 de abril, 2015).

Con la migración forzada, algunas de estas campesinas lograron estabilizarse por fuera de las fincas, otras, en cambio, siguieron trashumando en medio de incontables precariedades. Como están las cosas, el retorno no es una opción porque es peligroso y trae malos recuerdos. Al menos se reclamó la tierra, tal cual lo sostienen, otra cosa es que hasta ahora no les ha funcionado y, en definitiva, son procesos lentos, desconsiderados o incluso

[162 ] turbios, como alguna de ellas los califica (campesina de Urabá, comunicación personal, 11 de julio, 2019).

Mientras que para algunas de las campesinas la reclamación va a la par entre hombres y mujeres otras perciben lo contrario, debido a que los roles de género y su presunta indefensión en comparación con los varones. Aunque la solicitud saliera favorable, estas campesinas no quieren retornar, ya que les implicaría nuevos peligros, agravados con la amenaza de violencia sexual (campesina de Urabá, comunicación personal, 16 de julio, 2019).

\subsection{Mujeres ya restituidas en reconocimiento de titularidad de derechos y sujetos de reparación}

Tres campesinas de Granada y una de San Carlos fueron restituidas $y$, en todos los casos, los varones han ejercido un papel decisivo frente a la propiedad. Según lo relataron, a una de ellas le fue cedido el terreno informalmente, lo que más tarde se le convirtió en un problema al momento de reclamar. En otro caso, las campesinas heredaron la tierra de sus padres, pero sus hermanos hombres la administran. Finalmente, para una de ellas la finca siempre ha sido de su esposo, aunque hasta ese momento no se 
había escriturado la propiedad. Con la restitución de tierras se emprendieron procesos de formalización, pero a juicio de algunas testimoniantes hubiera bastado con la palabra del cónyuge para asegurar el predio.

Según las granadinas, el desplazamiento forzado en el municipio fue producto de la violencia generalizada a causa del conflicto armado, a veces, antepuesto al masivo abandono del campo debido a las dificultades económicas. En San Carlos sucedió algo parecido, de tal suerte que las confrontaciones armadas conllevaron el abandono forzado de las tierras, a lo cual la testimoniante se resistió por la falta de recursos materiales para salir de la localidad con sus hijos.

Obligadas por las necesidades económicas, las mujeres que emigraron retornaron a sus predios sin ningún tipo de acompañamiento. Más tarde, con la restitución de tierras, entre 2013 y 2014 se les formalizó la propiedad, en un caso como madre cabeza de hogar, mediante lo cual se acreditó el derecho a la reparación (campesina de San Carlos, comunicación personal, 4 de marzo, 2015), mientras que en los demás casos se reclamó en compañía del esposo. En el caso de las dos campesinas de Granada que reclamaron como hermanas y legítimas herederas del predio tras la muerte de sus padres, afirman que los proyectos productivos son la fortaleza de la reparación, pero se quejan de las continuas interrupciones para la entrega de los recursos. $\mathrm{Si}$ bien en estos casos el retorno no dependió de la restitución, ya que se dio de manera voluntaria y un par de años antes de que se promulgara la Ley, a través del mecanismo de reparación las campesinas formalizaron los bienes —a título personal o de la pareja-, a algunas se les construyó una nueva vivienda —no de la mejor calidad - y emprendieron iniciativas productivas (campesina de Granada, comunicación personal, 14 de junio, 2019).

\section{Discusión}

A continuación, se retoman los tres perfiles anteriores en aras de discutir los testimonios a la luz de las premisas teóricas que ayudan a dimensionar la magnitud de lo que está en juego en la reclamación de tierras por parte de las mujeres.

\subsection{Campesinas despojadas que no reclamaron sus tierras}

Casos de este tipo ilustran el predominio de la propiedad rural a cargo de los varones, sustentada desde la crianza que alienta el carácter dominante 
en los hombres y la sumisión en las mujeres (Bourdieu, 1998). Ante el fracaso de iniciativas legislativas, como la primera política de mujer rural en la década de 1980 o la débilmente regulada Ley 731 de 2002, en la ruralidad persiste la visión del varón como el legítimo dueño y señor de los medios de producción, mientras que las labores desempeñadas por mujeres pasan inadvertidas, incluso entre ellas mismas. A la cuestión naturalizada se suman las limitaciones mercantiles y estatales, poco favorables a las campesinas (Meertens, 2008 citada en Zuluaga, 2011).

En contextos de conflicto armado, la no titularidad de las mujeres incrementa su vulnerabilidad frente a la eventual pérdida de los esposos y al despojo; incluso teniendo patrimonio desconocen los linderos y el estado de las escrituras, lo que podría perjudicarlas en cuestión de reclamación o formalización. Ante la asimetría de género en las relaciones de poder en el campo, no basta con invocar el llamado «patrimonio familiar», porque a diferencia de lo que ocurre cuando las mujeres controlan la tierra, el patrimonio familiar no basta para contener el maltrato físico ni el desamparo material (Flores y Espejel, 2012; Zuluaga, 2011). Este continuo de exclusión se nutre de las posiciones de poder en las interacciones cotidianas, visibles en los regímenes patrimoniales que se afianzan en la división sexual del trabajo. En la ruralidad, el sesgo patrimonial de género se traduce en el aparente sinsentido de activar mecanismos jurídicos para titularle tierras a las campesinas, a quienes atañe lo doméstico y poco entienden de labores productivas remuneradas (Facio, 2002).

Al igual que los 7.7 millones de desplazados internos en Colombia (Rolón, 2018, diciembre 26), estas mujeres sancarlitanas huyeron de sus territorios para salvaguardar sus vidas y las de su familia. Según la Ruta Pacífica de las Mujeres (2013), a través del desplazamiento forzado se destruyen los arraigos de las poblaciones para usurpar las tierras e incluso el territorio en su relación geo-eco-antrópica (Sosa, 2012). En los lugares de acogida, los hombres y las mujeres no se acoplan de la misma forma: mientras las campesinas se adaptan más fácil que los varones en lo laboral, la pérdida de los nichos productivos desata en los hombres una pesada carga emocional, pues ven menoscabado su estatus de proveedores, a diferencia de las mujeres que son más recursivas para la generación de ingresos (Meertens, 2006).

Cuando regresaron a San Carlos a comienzos de la década del 2000 ya habían cesado las confrontaciones y las veredas se repoblaron progresivamente, 
lo que no significó el final del conflicto armado. Es común que durante los primeros años del retorno se prolongara la inestabilidad material. Al igual que el deseo inicial de estas campesinas, usualmente las mujeres prefieren permanecer en los lugares de reubicación, a menos que haya garantías de seguridad para sí mismas y los suyos (Meertens, 2006).

En cuanto a las tierras perdidas, estas mujeres no estaban conscientes de que fueron despojadas en medio de la zozobra para malvender las tierras. El desconocimiento de las modalidades de despojo implica, de una parte, el impedimento para las campesinas a ser reparadas y, por otro lado, la anulación del reconocimiento como sujetos de derecho por cuenta propia y a cargo del Estado.

\subsection{Campesinas reclamantes sin sentencia de restitución proferida}

Igual que otras campesinas, las reclamantes de Urabá dedicaron años de su vida al cuidado de la familia y al trabajo de la finca, si bien usualmente no han sido reconocidas como productoras (Thalia Kidder en Medellín Cano, 2015, abril 4). En el caso de estas mujeres, todas son reclamantes, pero ninguna es dueña del predio a restituir. En estos escenarios, el trabajo reproductivo es una barrera para la participación de las mujeres en el mercado laboral y, asimismo, les impide el acceso a otros derechos, frustrando de paso otras opciones de autorrealización (Kidder en Medellín Cano, 2015, abril 4).

Por tradición, el Estado no cuantifica estas actividades, con lo cual se agudiza la dicotomía entre lo público y lo privado, más las subsecuentes configuraciones sociales y atribuciones de género (Alviar, 2008). De acuerdo con el Plan de Naciones Unidas para el Desarrollo en Colombia (PNUD citado en Kidder, 2015), lo anterior mina la productividad del país, en vista de que las horas no remuneradas dedicadas al cuidado representan cerca de $20 \%$ del producto interno bruto nacional.

De cualquier forma, un llamado al reconocimiento económico y moral del papel de las mujeres en calidad de productoras, a sus aportes para la seguridad alimentaria o a las labores de cuidado que históricamente han desempeñado en ningún caso basta para desmontar los regímenes de género que las envuelven, entendidos como el complejo de relaciones que se desarrollan cotidianamente en las instituciones y que son el resultado de 
procesos más amplios de socialización, por lo que vienen cargados de discursos y prácticas que contribuyen a perpetuar la desigualdad entre hombres y mujeres (Connell, 1987). De hecho, estos factores suelen instrumentalizarse para abonar a las funciones domésticas en la preservación del rol reproductivo (León, 1986).

Estos regímenes de género, heredados desde la colonia (León, 2008), impiden que las mujeres gocen plenamente de los derechos, perpetuando así la exclusión del contrato social moderno ideado por varones. Lo anterior, a su vez, reproduce lo que se califica como violencia patrimonial de género (Flores y Espejel, 2012), afincada en el desconocimiento de los derechos de propiedad y de los beneficios derivados de la administración de los bienes (Zuluaga, 2011, p. 5952). Asimismo, a las mujeres se les dificulta «sentirse dueñas» de las parcelas, dejando a cargo de los varones la toma de decisiones, quienes por su parte no consideran sus necesidades (Zuluaga, 2011).

En medio de las disputas por la tierra, las reclamantes urabaenses fueron desplazadas y en sus demandas han atestiguado la brutalidad de la guerra con la presencia indiscriminada de actores armados que se oponen a la restitución (Ruta Pacífica de las Mujeres, 2013). Entre los responsables figuran estructuras

[166] paramilitares asociadas con el despojo en la región y también vinculados con la desarticulación de los procesos organizativos de mujeres alrededor de la exigibilidad de derechos sobre la tierra.

Otra cosa sucede en casos como el que vivió una de las reclamantes con el extinto Instituto Colombiano de la Reforma Agraria (Incora) (campesina de Urabá, comunicación personal, 4 de noviembre, 2015). En este proceso no hubo violencia de por medio, más bien se dio lo que Helena Alviar (2008) califica como las tensiones que origina el derecho de propiedad entre los grupos marginados, pues años atrás el Incora le arrebató las tierras a esta humilde familia para otorgársela a población indígena, también necesitada del terreno. La desarticulación estatal es igualmente responsable de la precarización con las tierras: en el afán de proteger los derechos de algunos se vulneran los derechos de otros.

Desde luego, en el Urabá antioqueño también se han registrado procesos de despojo en manos del Estado, el cual actúa deliberadamente para favorecer intereses particulares, ya sea mediante actos de corrupción o a través del diseño amañado de normas, en procesos de captura del Estado 
(Garay, 2008). Este tipo de cosas contribuyen a la concentración de la tierra con altos niveles de acaparamiento en Colombia, registrando a la fecha un Gini de 0,88 (Oxfam, 2016). ${ }^{1}$

Entretanto, las reclamantes continúan en espera de sentencia, a pesar del Ilamado de atención de la Corte Constitucional al Gobierno a finales de 2015 (Sentencia T-679) sobre la necesidad de agilizar los procesos de restitución, de cara al tiempo de vigencia de la Ley 1448. Para la ejecución eficiente de la política de restitución de tierras también se necesita desvertebrar y judicializar a las organizaciones criminales responsables del despojo, pues solo así se lograría detener el acaparamiento de la tierra, que no se elimina a la redistribución de la gran propiedad (Machado, 1998 citado en Meertens, 2006).

A lo anterior se añaden los factores «externos» en contra de las campesinas, a las que por sí mismas no se les reconoce el derecho a la tierra, exigiéndoseles una serie de trámites civiles para comprobar la relación con el varón (Parada, investigadora del Observatorio de Restitución y Derechos de Propiedad Agraria, comunicación personal, 12 de mayo, 2014). Lo dicho, más la dificultad de las testimoniantes para autorreconocerse como sujetos de derecho frente a la tierra, entorpece aún más los procesos de restitución para las mujeres.

\subsection{Mujeres ya restituidas con titularidad de derechos sobre la tierra}

De acuerdo con Carmen Deere y Magdalena León (2000), aunque a partir de la década de 1980 comenzaron a promulgarse abundantes normas en Latinoamérica a favor de la igualdad de género, en la práctica persisten las brechas entre hombres y mujeres, con serias desventajas para las segundas en aspectos como la titularidad y administración de la tierra.

Según datos del último censo nacional agropecuario (Oxfam, 2017), en cerca de $60 \%$ del área rural dispersa del país los hombres toman las decisiones de producción sobre la tierra, $24 \%$ a cargo de las mujeres y 16,5\% entre ambos. Las campesinas solas tienen menor acceso a crédito, maquinaria y

\footnotetext{
${ }^{1}$ El coeficiente de Gini para la tierra es un indicador entre 0 y 1 , donde 1 representa la máxima desigualdad, lo que quiere decir que un Gini de tierra para Colombia de 0,88 es una alerta sobre los altos niveles de concentración de este recurso en el país (Oxfam, 2016).
} 
asistencia técnica, mientras que cuando las decisiones se toman entre los dos tienen mejores resultados. Este contexto no es ajeno a la restitución, lo que deja en evidencia los rezagos del sistema judicial para entender el concepto de propietaria, poseedora u ocupante, disminuidos en los casos de parejas porque según los operadores - jueces y funcionarios administrativos- la propiedad en cabeza de los hombres equivale al beneficio de la compañera. De los cuatro casos de mujeres restituidas, dos de las sentencias priorizan la versión de los esposos y reparan a título de la pareja. Esto a su vez puede entenderse como el enfoque familista del Estado, exceptuando los casos en los que las y los funcionarios se salen del esquema y reconocen a las mujeres como titulares de derecho y propietarias de la tierra sin mayores preámbulos.

En el censo no se pregunta por la propiedad formal sino por la tenencia, arrojando que el tamaño de la tierra en cabeza de mujeres es menor que en el caso de los hombres: casi $74 \%$ de las mujeres tienen menos de 5 ha en comparación con $62 \%$ de los hombres. En el rango entre 5 y 100 ha, la participación de los hombres es mucho mayor. Lo mismo sucede con las testimoniantes restituidas, para las que el promedio de la extensión del terreno es igual o menor a 5 ha. Finalmente, en el censo sobresale la creciente participación de las mujeres como jefas de hogar, de manera que en 2005 82\% de los hombres asumían la jefatura, pasando ahora a 72,2\%. Entre las cuatro entrevistadas restituidas, dos asumen la jefatura familiar, sin embargo, esto no les ha garantizado la igualdad de condiciones para acceder a mejores formas de trabajar los predios. Aunque en los casos estudiados hay dos mujeres con jefatura, las demás salen restituidas bajo la figura de la unidad familiar.

Tras la puesta en marcha de la restitución en el Oriente antioqueño un alto porcentaje de las víctimas ha iniciado la ejecución de un proyecto productivo, por un valor aproximado de 24 millones de pesos. Para Alejandra Coll (2015) los proyectos cumplen con el enfoque transformador de la Ley 1448 de 2011, pero es necesario analizar a fondo si las iniciativas ofertadas a estas campesinas — ganadería, café y caña— efectivamente satisfacen sus necesidades productivas y de perdurabilidad.

Pese a las dificultades, los proyectos se han venido sosteniendo, aunque el tamaño de los terrenos restituidos no siempre equivale a una Unidad Agrícola Familiar (UAF) (Ley 160 de 1994), dado que eran propiedades privadas que nunca tuvieron el tamaño de la UAF regional. De igual forma, la calidad de las viviendas entregadas tras la sentencia no es la mejor, por lo 
que en ambos casos podría comprometerse la integralidad de la reparación y la sostenibilidad en el largo plazo de las iniciativas productivas, además de abrir futuras brechas para el despojo de tierras a través de la compra masiva de pequeños fundos improductivos (Uribe, investigadora del Observatorio de Restitución y Derechos de Propiedad Agraria, comunicación personal, 12 de mayo, 2014).

A lo anterior se suma el hecho de que si estas mujeres no se insertan en ninguna cadena asociativa para equilibrar la competencia del mercado, al final la restitución solo contribuirá a perpetuarlas en la pobreza (Gutiérrez, ex funcionaria pública, comunicación personal, 12 de agosto, 2019). En ocasiones, lo anterior se cruza con la ubicación problemática de los terrenos, pues además de la inaccesibilidad física, muchas de estas áreas no pasan por un reordenamiento social del territorio que favorezca la reconstrucción del tejido social (Uribe, investigadora del Observatorio de Restitución y Derechos de Propiedad Agraria, 12 de mayo, 2014).

Frente a ello, la política de restitución de tierras aspira a trascender la entrega particular de los predios y reconstruir las comunidades. La reparación gota a gota no ha logrado resarcir estas necesidades porque entiende la propiedad como un asunto individual. En estos términos, la problemática de las campesinas termina reduciéndose a un tema de mujeres con escritura, a quienes se les dificultará constituirse como sujetos de derecho más allá de una nominación.

Con todo lo dicho, las testimoniantes afirman que la restitución ha sido relativamente sencilla, semejante al criterio de Forjando Futuros (s. f.) respecto a la fluidez de la reparación en el Oriente antioqueño, caracterizado por el abandono forzado y con escasos oponentes a las demandas. De la mano se dieron los retornos en la región, con $82 \%$ antes de las sentencias, apoyados en programas de las alcaldías de Medellín, Granada y San Carlos en los planes de desarrollo municipal 2008-2015.

Sin embargo, acceder a la propiedad mediante la reparación es ambivalente. Por un lado, las mujeres han hallado una oportunidad para la exigibilidad de sus derechos; en el caso de las campesinas reconocidas como víctimas del conflicto armado, funciona una especie de esencialismo estratégico (Gayatry Spivak citada en Lamas, 2006) para el reconocimiento como sujetos de derecho respecto a la tierra. No obstante, hay una línea delgada entre la victimización estratégica para el reconocimiento de la 
titularidad de derechos vía restitución y la victimización del esencialismo sustancialista (Spivak citada en Lamas, 2006), apegado a supuestas esencias como la fragilidad femenina, lo que podría devenir en la revictimización y en el abatimiento moral.

Bajo este manto se problematiza la victimización estratégica de las mujeres campesinas para el reconocimiento de la titularidad de derechos mediante la reparación en el conflicto armado. Cabe entonces preguntarse, de acuerdo con Judith Butler (1989a citada en Mattio, 2009, p. 4) respecto a la identidad como «víctimas»: «iQué uso será legislado y qué juegos se producirán entre legislación y uso de tal manera que los usos instrumentales de "identidad" no se conviertan en imperativos de regulación?».

Lo anterior permite volver sobre la victimización, una nominación transitoria en medio de un proyecto más amplio de subjetivación jurídica y política. Finalmente, queda el peligro de exotizar la guerra como el escenario para que las mujeres puedan negociar transformaciones en sus vidas, dejando a un lado los daños cotidianos que también urgen en soluciones. Como sea, tampoco hay que desconocer la existencia del conflicto armado, porque de esto depende la impartición de justicia para los victimarios (Alviar y Jaramillo, [170] 2012).

\subsection{Qué esperar de la restitución de tierras para las mujeres en clave de construcción de paz territorial}

La restitución de tierras se retomó en la Reforma Rural Integral pactada en el Acuerdo de Paz. Tras ocho años de implementación de la Ley 1448 de 2011, a 2020 se han fallado 5793 sentencias, con las cuales se les ha reconocido 9925 títulos de propiedad a mujeres, frente a 9536 para varones, equivalentes a 380208 hectáreas restituidas (Fundación Forjando Futuros, s. f.) de un total de entre 6 y 8 millones de hectáreas despojadas o abandonadas. A pesar de las cifras, reconforta saber que la restitución avanza a favor de las campesinas, lo que en otros tiempos era impensable. Hasta hoy, el Oriente antioqueño aventaja significativamente al Urabá en el número de sentencias proferidas, fundamentalmente por las características del desarraigo en cada área.

Dentro de las estrategias del Acuerdo para la construcción de paz están los Programas de Desarrollo con Enfoque Territorial (PDET), distribuidos en Antioquia en el Bajo Cauca, Nordeste y Urabá. Dichos programas se diseñaron 
para ejecutarse en los 170 municipios del país más afectados por el conflicto armado, mediante los cuales se busca involucrar a las comunidades para convenir las estrategias de desarrollo y construcción de paz. En la actualidad, Urabá tiene más de 6300 solicitudes de restitución y hasta el momento, no se han resuelto ni $5 \%$ de estas. Adicionalmente, los PDET parece que no pasan de ser meros ejercicios consultivos con la comunidad que no logran materializarse en la práctica.

El asesinato de líderes sociales también ha marcado al Urabá, aunque sin extinguir las iniciativas de construcción de paz territorial, sobre todo, iniciativas organizadas de las que forman parte algunas de las testimoniantes urabaenses. Otras no participan del activismo, pero desde su esfera individual confían en el Acuerdo de Paz, porque de hecho ya han notado cambios positivos en sus entornos (campesina de Urabá, comunicación personal, 11 de julio, 2019). De su lado, las campesinas del Oriente antioqueño entienden que la construcción de paz se gesta desde las prácticas cotidianas, con la gente en las veredas que de a poco han venido recomponiendo sus proyectos de vida colectivos (campesina de Granada, comunicación personal, 14 de junio, 2019).

En la actualidad Antioquia atraviesa una compleja situación de derechos humanos, lo que difícilmente la ubica como un escenario prometedor para la implementación de los acuerdos (Gutiérrez, ex funcionaria pública, comunicación personal, 12 de agosto, 2019). A pesar de ello, el testimonio de estas mujeres muestra su compromiso con la paz positiva, que a diferencia de la paz negativa no se limita a entender la paz como la ausencia de confrontaciones, sino como apuesta continua por el bienestar personal y colectivo, por la tranquilidad y la solidaridad. Al final, la paz no es «nada del otro mundo», como diría una de las testimoniantes de Oriente (campesina de Granada, comunicación personal, 14 de junio, 2019): Se trata de vivir bien, sin que unos pocos tengan mucho, a costa del sufrimiento y la precariedad de otros y otras.

\section{Conclusiones}

La tierra es la base del conflicto armado en el país y, en buena medida, la clave para resolverlo. Parece un lugar común en la literatura académica, pero ayuda a simplificar años de historia colombiana, durante los cuales las 
mujeres han resultado fuertemente desfavorecidas. Pensar en la titularidad de derechos de propiedad para las campesinas es, sin duda, el primer paso dentro de un amplio trayecto para recomponer el campo en el país.

Desde luego, un título de propiedad no basta, sin embargo, es una pieza clave para empoderar a las mujeres en la reconstrucción de los entornos devastados por la guerra. Distintas experiencias han mostrado el valor de la participación activa de las mujeres en estos procesos, por la capacidad de estimular la reconfiguración del tejido social, por el fuerte compromiso de muchas para activar procesos de memoria histórica y por liderar proyectos productivos asociativos, la custodia de semillas nativas, la salvaguarda de la soberanía alimentaria local, además de liderar iniciativas de construcción de paz territorial.

En este sentido, la restitución de tierras se entiende como un mecanismo a través del cual las campesinas pueden dignificar el trabajo que han desempeñado anónimamente en las fincas durante generaciones. Es una cuestión de justicia de género, pero, ante todo, una puerta que se abre para el respaldo material de las mujeres en medio de estructuras tan asimétricas como el derecho y la distribución de la tierra. En definitiva, se trata de un paso obligado para transitar de la victimización e invisibilización hacia una vida propositiva y autodeterminada en contextos que privilegian la base material para la toma de decisiones.

\section{Referencias bibliográficas}

1. Albán, Álvaro. (2011). Reform and self defeating agrarian reform in Colombia. Revista de Economía Institucional, 13 (24), pp. 327-356.

2. Alcaldía El Peñol. (s. f.). Galería de mapas. Departamento de Antioquia. Subregiones y municipios. Recuperado de http://www.elpenol-antioquia.gov.co/ MiMunicipio/GaleriaDeMapas/Mapa\%20Antioquia.jpg

3. Rolón Salazar, Mariana. (2018, diciembre 26). Hay más víctimas de desplazamiento forzado en Colombia que número de habitantes en Costa Rica. ACNUR. Recuperado de https://www.acnur.org/noticias/noticia/2018/12/5c243ef94/ hay-mas-victimas-de-desplazamiento-forzado-en-colombia-que-numero-dehabitantes.html

4. Alviar, Helena. (2008). Propiedad. En: Jaramillo, Isabel Cristina y Sáez, Macarena (eds.). La mirada de los jueces. Género en la jurisprudencia latinoamericana (pp. 487-548). Bogotá, D. C.: Siglo del Hombre. 
Restitución de tierras en Antioquia, Colombia. Base para la consolidación del sujeto...

5. Alviar, Helena y Jaramillo, Isabel Cristina. (2012). Feminismo y crítica jurídica. El análisis distributivo como alternativa crítica al legalismo liberal. Bogotá, D. C.: Siglo del Hombre.

6. Amorós, Celia. (2000). Tiempo de feminismo. Sobre feminismo, proyecto ilustrado y postmodernidad. Madrid: Cátedra.

7. Naciones Unidas. Asamblea General. Resolución 60/147. (16 de diciembre de 2005). Principios y directrices básicos sobre el derecho de las víctimas de violaciones manifiestas de las normas internacionales de derechos humanos y de violaciones graves del derecho internacional humanitario a interponer recursos y obtener reparaciones. Recuperado de https://www.ohchr.org/SP/Professionallnterest/Pages/ RemedyAndReparation.aspx

8. Bourdieu, Pierre. (1998). La dominación masculina. Barcelona: Anagrama.

9. Centro Nacional de Memoria Histórica (CNMH). (2013). La política de reforma agraria y tierras en Colombia. Esbozo de una memoria institucional. Bogotá, D. C.: Imprenta Nacional. Recuperado de http://www.centrodememoriahistorica.gov.co/ descargas/informes2013/agraria/politica-agraria-tierras.pdf

10. Coll, Alejandra. (2015). Acceso de las mujeres a la tierra: realidades de la restitución y el desarrollo rural para las mujeres en Santander, Antioquia y Cauca. Bogotá, D. C: Ruta Pacífica de las Mujeres y Comunitar.

11. Colombia. Congreso de la República. Ley 160. (5 de agosto de 1994). Por la cual se crea el Sistema Nacional de Reforma Agraria y Desarrollo Rural Campesino, se establece un subsidio para la adquisición de tierras, se reforma el Instituto Colombiano de la Reforma Agraria y se dictan otras disposiciones. Recuperado de http://www. secretariasenado.gov.co/senado/basedoc/ley_0160_1994.html

12. Colombia. Congreso de la República. Ley 1448. (10 de junio de 2011). Por la cual se dictan medidas de atención, asistencia y reparación integral a las víctimas del conflicto armado interno y se dictan otras disposiciones. Recuperado de https://www. unidadvictimas.gov.co/sites/default/files/documentosbiblioteca/ley-1448-de-2011.pdf

13. Colombia. Corte Constitucional. Sentencia T-679. (3 de noviembre de 2015). Recuperado de https://www.corteconstitucional.gov.co/relatoria/2015/t-679-15.htm

14. Comisión Colombiana de Juristas. (2011). La política agraria y los derechos de las mujeres en Colombia. Recuperado de http://www.coljuristas.org/documentos/ libros_e_informes/la_politica_agraria_y_los_derechos_de_las_mujeres.pdf

15. Connell, Raewyn. (1987). Gender and Power. Stanford: Stanford University.

16. Deere, Carmen Diana y León, Magdalena. (2000). Género, propiedad y empoderamiento: Tierra, Estado y mercado en América Latina. Bogotá, D. C.: Universidad Nacional.

17. El Espectador. (2019, marzo 6). Colombia, México y Brasil encabezan lista mundial de líderes sociales asesinados. El Espectador. Recuperado de https://www. elespectador.com/noticias/el-mundo/colombia-mexico-y-brasil-encabezan-listamundial-de-lideres-sociales-asesinados-articulo-843482 
18. Estrada, María del Rosario y Rodríguez, Nadia Margarita. (2014). La política de tierras para la población desplazada 2001-2011: de la protección a la restitución. Estudios Socio-Jurídicos, 16 (1), pp. 75-121. https://doi.org/10.12804/esj16.1.2014.02

19. Facio, Alda. (2002). Con los lentes del género se ve otra justicia. El Otro Derecho, 28, pp. 85-102.

20. Flores, Aurelia y Espejel, Adelina. (2012). Violencia patrimonial de género en la pequeña propiedad. El Cotidiano, 174, pp. 5-17.

21. Fraser, Nancy. (1997). Iustitia Interrupta. Reflexiones críticas desde la posición "postsocialista». Bogotá, D. C.: Siglo del Hombre.

22. Fundación Forjando Futuros. (s. f.). Sistema de Información Sembrando Paz. Recuperado de http://sifff.eaconsultores.com.co/Datos/Index

23. Garay Salamanca, Luis Jorge (dir.). (2008). La captura y reconfiguración cooptada del Estado en Colombia. Bogotá, D. C.: Fundación Método, Fundación Avina y Transparencia por Colombia. Recuperado de https://moe.org.co/home/ doc/moe_mre/CD/Otros $\% 20$ mapas $\% 20 y \% 20$ documentos/Captura $\% 20 y \% 20$ Reconfiguraci\%F3n\%20Cooptada\%20del\%20Estado\%20Colombiano.pdf

24. Guzmán, Diana y Chaparro, Nina. (2013). Restitución de tierras y enfoque de género. Bogotá, D. C.: Dejusticia. Recuperado de https://www.dejusticia.org/wpcontent/uploads/2017/04/fi_name_recurso_365.pdf

25. Ibáñez, Ana María y Querubín, Pablo. (2004). Acceso a tierras y desplazamiento forzado en Colombia. Documento Cede, 23, Recuperado de http:// [174] economia.uniandes.edu.co/publicaciones/d2004-23.pdf

26. Medellín Cano, María José. (2015, abril 4). El trabajo invisible de las mujeres rurales. El Espectador. Recuperado de http://www.elespectador.com/noticias/ actualidad/el-trabajo-invisible-de-mujeres-rurales-articulo-553139

27. Lamas, Marta. (2006). Género: algunas precisiones conceptuales y teóricas. En: Feminismo: transmisiones y retransmisiones. México: Taurus.

28. León, Magdalena. (1986). Política agraria en Colombia y debate sobre políticas para la mujer rural. En: Deere, Carmen Diana y León, Magdalena (eds.). La mujer y la política agraria en América Latina (pp. 43-64). Bogotá, D. C.: Siglo Xxı.

29. León, Magdalena. (2008). La propiedad como bisagra para la justicia de género. En: Castro, Roberto y Casique, Irene (eds.). Estudios sobre cultura, género y violencia contra las mujeres (pp. 291-318). México, D. F.: Universidad Nacional Autónoma de México. Recuperado de http://www.crim.unam.mx/drupal/crimArchivos/Colec Dig/2007/Roberto_Castro/9_La_propiedad_como_bisagra_para_la_justicia_de_ genero.pdf

30. Machado, Absalón. (2011). La tierra y el desarrollo humano. Semillas, 44-45. Recuperado de http://www.semillas.org.co/apc-aa-files/353467686e6667686b6c676 668f16c6c/articulo\%2003.pdf

31. Mattio, Eduardo. (2009). ¿Esencialismo estratégico? Un examen crítico de sus limitaciones políticas. Construyendo Nuestra Interculturalidad, 4 (5), pp. 1-11. 
Restitución de tierras en Antioquia, Colombia. Base para la consolidación del sujeto...

32. Meertens, Donny. (2006). Tierra, derechos y género. Leyes, políticas y prácticas en contextos de guerra y paz. Informe final de la consultoría sobre derechos de las mujeres a la tierra. Recuperado de http://www.bdigital.unal.edu.co/51537/1/ tierraderechosygenero.pdf

33. Meertens, Donny. (2011). La dimensión de género en el desplazamiento interno: Respuestas institucionales en el caso colombiano. Anuario de Acción Humanitaria y Derechos Humanos, pp. 41-52. Recuperado de http://www.corteidh. or.cr/tablas/r27837.pdf

34. Oxfam. (2016). Desterrados: Tierras, poder y desigualdad en América Latina. Recuperado de https://www-cdn.oxfam.org/s3fs-public/file_attachments/desterradosfull-es-29nov-web_0.pdf

35. Oxfam. (2017). Radiografía de la desigualdad: Lo que nos dice el último censo agropecuario sobre la distribución de la tierra en Colombia. Recuperado de https:// www-cdn.oxfam.org/s3fs-public/file_attachments/radiografia_de_la_desigualdad.pdf

36. Programa de las Naciones Unidas para el Desarrollo (PNUD). (2011). Colombia rural: Razones para la esperanza. Informe Nacional de Desarrollo Humano. Bogotá, D. C.: INDH PNUD. Recuperado de http://hdr.undp.org/sites/default/files/ nhdr_colombia_2011_es_low.pdf

37. Rodríguez, Claudia. (2014). La ley de restitución de tierras desde la perspectiva de género. Justicia Juris, 10 (1), pp. 53-65. Recuperado de http://ojs.uac.edu.co/index. php/justicia-juris/article/viewFile/299/280

38. Ruta Pacífica de las Mujeres. (2013). La verdad de las mujeres víctimas del conflicto armado en Colombia (versión resumida). Bogotá, D. C.: Ruta Pacífica de las Mujeres.

39. Sosa, Mario. (2012). ¿Cómo entender el territorio? Ciudad de Guatemala: Cara Parens.

40. Uprimny, Rodrigo y Sánchez, Nelson. (2010). Los dilemas de la restitución de tierras en Colombia. Estudios Socio-Jurídicos, 12 (2), pp. 305-342. Recuperado de https://revistas.urosario.edu.co/index.php/sociojuridicos/article/view/1373/1263

41. Valdivieso, Andrés Mauricio. (2012). La justicia transicional en Colombia: Los estándares internacionales de derechos humanos y derecho internacional humanitario en la política de Santos. Papel Político, 17 (2), pp. 621-653.

42. Vélez, Ana Cristina. (2013). A la zaga de lo político: La agenda mediática de la Ley de Víctimas y Restitución de Tierras. Co-herencia, 10 (18), 79-103. https://doi. org/10.17230/co-herencia.10.18.3

43. Zarka, Yves Charles. (1999). La invención del sujeto de derecho. Isegoría, 20, pp. 31-49. https://doi.org/10.3989/isegoria.1999.i20.91

44. Zuluaga, Gloria. (2011). El acceso a la tierra: Asunto clave para las mujeres campesinas en Antioquia, Colombia. Revista Facultad Nacional de Agronomía Medellín, 64 (1), pp. 5953-5954. 